\title{
PREPARATION OF A MODIFIED ELECTRODE FOR THE DETERMINATION OF LEVOFLOXACIN
}

\author{
Ayça ATILIR ÖZCAN ${ }^{1}$, Mustafa GÜRBÜZ ${ }^{2}$, Ali ÖZCAN 1, * \\ ${ }^{1}$ Department of Chemistry, Faculty of Science, Anadolu University, Eskişehir, Turkey \\ ${ }^{2}$ Department of Chemistry, Graduate School of Sciences, Anadolu University, Eskişehir, Turkey
}

\begin{abstract}
In this study, modification of glassy carbon (GC) electrode with electrochemically reduced graphene oxide (ERGO) and acid treated multi-walled carbon nanotubes (A-MWCNT) was investigated for the voltammetric determination of levofloxacin (LEV) in body fluids and pharmaceutical products. Different combinations of GO, ERGO, MWCNT and A-MWCNT were searched and the best results were obtained with GC/ERGO/A-MWCNT electrode. The modified electrode showed electrocatalytic activity towards LEV oxidation by increasing oxidation peak currents 293 times. Characterizations of the modified electrode was performed with cyclic voltammetry, electrochemical impedance spectroscopy and Raman measurements. The highest oxidation peak current was observed at $\mathrm{pH}$ value of 2.0. The oxidation peak currents of LEV increased linearly with the concentration of LEV in the range of $0.01 \mu \mathrm{M}$ and $10 \mu \mathrm{M}$. The detection limit of the prepared sensor was determined as $0.0063 \mu \mathrm{M}$. After three weeks' storage, the prepared electrode showed high stability by preserving $93 \%$ of its original activity towards $1.0 \mu \mathrm{M} \mathrm{LEV}$. The modified electrode successfully discriminates the voltammetric response of LEV from that of other fluoroquinolone antibiotics (enoxacin, norfloxacin and ciprofloxacin). Finally, the performance of the prepared electrode was tested in the determination of LEV in human blood serum, urine and pharmaceutical samples.
\end{abstract}

Keywords: Electrochemical sensor, Graphene oxide, Levofloxacin, Multi-walled carbon nanotube, Voltammetry

\section{INTRODUCTION}

Levofloxacin (LEV) is a third-generation broad-spectrum synthetic antibiotic, which can be used with oral and intravenous ways. It is very effective against gram-positive and gram-negative aerobic bacteria as well as Helicobacter pylori [1,2]. LEV has been widely used in human and animals. Although LEV is generally good tolerated, in some instances it may cause serious side effects like tendon ruptures, heart problems and Stevens-Johnson syndrome [3]. Therefore, determination of LEV in body fluids and pharmaceutical formulations is a very important issue. Though there are many available methods for the determination of LEV, electrochemical methods can be seen promising alternatives due to their fast, simple, inexpensive, sensitive and selective characteristics [2,4-7]. While the electrochemical methods have many advantages, conventional electrodes limit their application in analytical chemistry because of their common drawbacks such as high over-potential and low surface area. Different substances were investigated to modify the conventional electrodes. In this frame, molecularly imprinted polymers $[3,8]$, $\mathrm{Ag}$ nanoparticles/electrospun $\mathrm{CeO}_{2}-\mathrm{Au}$ composite nanofibers [9], poly(o-aminophenol)/MWCNTs composite [10] modified electrodes were developed for the voltammetric determination of LEV.

Graphene and carbon nanotubes are the most widely investigated materials to increase the performance of the electrochemical methods. Graphene, composed of a one atom-thick sheet of $\mathrm{sp}^{2}$ bonded carbon atoms, has been searched lately because of its unique properties such as high surface area, high conductivity and high chemical stability [11-13]. The effectiveness of graphene was tested in many different fields like supercapacitors [14], batteries [15] and solar cells [16]. Multi-walled carbon nanotubes (MWCNTs) were another popular carbon nano-materials studied last years because of their

*Corresponding Author: aozcan3@anadolu.edu.tr 
unusual electronic and mechanical properties. They were also tested in many fields like graphene [1719]. Both graphene and MWCNTs have been intensively investigated as a modifier to promote electrontransfer rates at electrode/solution interfaces in electroanalytical applications. They also offer high effective surface area, which increases the sensitivity of the electroanalytical methods, in addition to higher electron-transfer rates. Moreover, they allow modifying electrode surfaces with different functional groups, which increase the affinity of analytes towards electrode surfaces. While graphene and MWCNT have been widely used in the determination of many analytes, there was little attention given into the determination of LEV.

In this study, we have investigated the modification of glassy carbon (GC) electrode with electrochemically reduced graphene oxide (ERGO) and acid treated multi-walled carbon nanotube (AMWCNT) for the voltammetric determination of LEV in different samples such as urine, blood serum and pharmaceutical samples. The best results were obtained by the combination of ERGO with AMWCNT. The characterization of the modified electrode was performed. The experimental variables that affect the LEV sensitivity of GC/ERGO/A-MWCNT were examined. The highest peak currents for LEV oxidation were obtained at $\mathrm{pH}$ value of 2.0. The prepared GC/ERGO/A-MWCNT successfully discriminates the oxidation potential of LEV from that of other fluoroquinolone antibiotics of ciprofloxacin, norfloxacin and enoxacin. The analytical application of the GC/ERGO/A-MWCNT was successfully tested in real samples.

\section{EXPERIMENTAL SECTION}

\subsection{Chemicals and Apparatus}

Levofloxacin (LEV, 99\%) and other fluoroquinolone antibiotics were obtained from Fluka. Graphene oxide $\left(2 \mathrm{mg} \mathrm{mL}^{-1}\right.$ dispersion in $\left.\mathrm{H}_{2} \mathrm{O}\right)$ and multi-walled carbon nanotube $(95 \%$, OD x L $=6.9 \mathrm{~nm} \times 5$ $\mu \mathrm{m})$ were purchased from Sigma-Aldrich. Ultra-pure deionized water was obtained by a Sartorius ultrapure water system (Germany).

A conventional five-necked electrochemical cell was used in the experiments. A saturated calomel electrode (Gammry Instruments, USA) and a platinum wire were used as the reference and auxiliary electrodes, respectively. A glassy carbon (GC, $3.0 \mathrm{~mm}, \mathrm{BASi}$, USA) electrode was served as a working electrode. Electrochemical measurements were performed with an Autolab PGSTAT 100 model potentiostat (Metrohm Autolab, The Netherlands). Raman spectrums were obtained by a Raman spectrometer (Senterra; Bruker Optics GmbH, Ettlingen, Germany). A 532-nm laser line was used as an excitation source and light power was kept at $10 \mathrm{~mW}$. The resolution of the laser is $3 \mathrm{~cm}^{-1}$ in the spectral region of 400-4400 $\mathrm{cm}^{-1}$. The signals were collected by a charge-coupled device (CCD) detector.

\subsection{Preparation of GC/ERGO/A-MWCNT}

Acid-activated multi-walled carbon nanotube (A-MWCNT) was prepared by reacting $50.0 \mathrm{mg}$ pristine MWCNT with $4.0 \mathrm{M} \mathrm{HNO}_{3}$ for 4 hours at room temperature. After that, A-MWCNT was filtered and washed with double-distilled water. A-MWCNT dispersion was prepared by dispersing $10 \mathrm{mg}$ AMWCNT in $10 \mathrm{~mL}$ dimethylformamide. GC surface was polished subsequently with $1.0 \mu \mathrm{m}, 0.3 \mu \mathrm{m}$ and $0.05 \mu \mathrm{m}$ alumina powder and cleaned by sonication in methanol and deionized water for $3 \mathrm{~min}$. After that, $10 \mu \mathrm{L}$ of $1.0 \mathrm{mg} \mathrm{mL}^{-1}$ graphene oxide dispersion was dropped on GC electrode. After drying, the graphene oxide was electrochemically reduced by potential cycling between $0.0 \mathrm{~V}$ and $-1.5 \mathrm{~V}$ for 10 scans with a scan rate of $0.05 \mathrm{~V} \mathrm{~s}^{-1}$ to obtain GC/ERGO. A $10 \mu \mathrm{L}$ of $1.0 \mathrm{mg} \mathrm{mL}^{-1}$ A-MWCNT dispersion was dropped on GC/ERGO to obtain GC/ERGO/A-MWCNT. Different modified electrodes were also prepared (Table 1), but GC/ERGO/A-MWCNT of all the studied electrodes showed the highest electrochemical response towards LEV. 
Atılır Özcan et al. / Anadolu Univ. J. of Sci. and Technology A - Appl. Sci. and Eng. 18 (5) - 2017

Table 1. Preparation conditions of the examined electrodes

\begin{tabular}{|c|c|}
\hline Electrode & Preparation conditions \\
\hline $\mathrm{GC} / \mathrm{GO}$ & $10 \mu \mathrm{L}$ of $1.0 \mathrm{mg} \mathrm{L}^{-1} \mathrm{GO}$ dispersion was dropped on GC. \\
\hline GC/A-MWCNT & $10 \mu \mathrm{L}$ of $1.0 \mathrm{mg} \mathrm{L}^{-1} \mathrm{~A}-\mathrm{MWCNT}$ dispersion was dropped on $\mathrm{GC}$. \\
\hline GC/ER-A-MWCNT & $\begin{array}{l}10 \mu \mathrm{L} \text { of } 1.0 \mathrm{mg} \mathrm{L}^{-1} \text { A-MWCNT dispersion was dropped on GC. After that, the } \\
\text { electrode was electrochemically reduced. }\end{array}$ \\
\hline $\mathrm{GC} /(\mathrm{GO}+\mathrm{A}-\mathrm{MWCNT})$ & $10 \mu \mathrm{L}$ of mixture of $1.0 \mathrm{mg} \mathrm{L}^{-1} \mathrm{GO}$ and A-MWCNT was dropped on GC. \\
\hline $\begin{array}{l}\mathrm{GC} / \mathrm{ER}-(\mathrm{GO}+\mathrm{A}- \\
\mathrm{MWCNT})\end{array}$ & $\begin{array}{l}10 \mu \mathrm{L} \text { of mixture of } 1.0 \mathrm{mg} \mathrm{L}^{-1} \mathrm{GO} \text { and A-MWCNT was dropped on GC. After } \\
\text { that, the electrode was electrochemically reduced. }\end{array}$ \\
\hline $\begin{array}{l}\text { GC/ERGO/ER-A- } \\
\text { MWCNT }\end{array}$ & $\begin{array}{l}10 \mu \mathrm{L} \text { of } 1.0 \mathrm{mg} \mathrm{L}^{-1} \mathrm{GO} \text { dispersion was dropped on GC. Firstly, the electrode was } \\
\text { electrochemically reduced. After that, } 10 \mu \mathrm{L} \text { of } 1.0 \mathrm{mg} \mathrm{L}^{-1} \mathrm{~A}-\mathrm{MWCNT} \text { dispersion } \\
\text { was dropped on GC/ERGO. Finally, a reduction step was also applied as in the first } \\
\text { stage. }\end{array}$ \\
\hline $\begin{array}{l}\mathrm{GC} / \mathrm{ERGO} /(\mathrm{A}- \\
\mathrm{MWCNT}+\mathrm{GO})\end{array}$ & $\begin{array}{l}10 \mu \mathrm{L} \text { of } 1.0 \mathrm{mg} \mathrm{L}^{-1} \mathrm{GO} \text { dispersion was dropped on GC. Firstly, the electrode } \\
\text { was electrochemically reduced. After that, } 10 \mu \mathrm{L} \text { of mixture of } 1.0 \mathrm{mg} \mathrm{L}^{-1} \mathrm{GO} \\
\text { and A-MWCNT was dropped on GC/ERGO. }\end{array}$ \\
\hline $\begin{array}{l}\text { GC/ERGO/ER-(A- } \\
\text { MWCNT+GO) }\end{array}$ & $\begin{array}{l}10 \mu \mathrm{L} \text { of } 1.0 \mathrm{mg} \mathrm{L}^{-1} \mathrm{GO} \text { dispersion was dropped on GC. Firstly, the electrode } \\
\text { was electrochemically reduced. After that, } 10 \mu \mathrm{L} \text { of mixture of } 1.0 \mathrm{mg} \mathrm{L}^{-1} \mathrm{GO} \\
\text { and A-MWCNT was dropped on GC/ERGO. Finally, a reduction step was also } \\
\text { applied as in the first stage. }\end{array}$ \\
\hline ER-GC/A-MWCNT & $\begin{array}{l}\text { Firstly, GC electrode was electrochemically reduced. After that, } 10 \mu \mathrm{L} \text { of } 1.0 \mathrm{mg} \\
\mathrm{L}^{-1} \text { A-MWCNT dispersion was dropped on ER-GC. }\end{array}$ \\
\hline ER-GC/ER-A-MWCNT & $\begin{array}{l}\text { Firstly, GC electrode was electrochemically reduced. After that, } 10 \mu \mathrm{L} \text { of } 1.0 \mathrm{mg} \\
\mathrm{L}^{-1} \mathrm{~A}-\mathrm{MWCNT} \text { dispersion was dropped on ER-GC. Finally, a reduction step was } \\
\text { also applied as in the first stage. }\end{array}$ \\
\hline GC/A-MWCNT/GO & $\begin{array}{l}\text { Firstly, } 10 \mu \mathrm{L} \text { of } 1.0 \mathrm{mg} \mathrm{L}^{-1} \text { A-MWCNT dispersion was dropped on GC. After } \\
\text { that, } 10 \mu \mathrm{L} \text { of } 1.0 \mathrm{mg} \mathrm{L}^{-1} \mathrm{GO} \text { dispersion was dropped on GC/A-MWCNT. }\end{array}$ \\
\hline GC/A-MWCNT/ERGO & $\begin{array}{l}\text { Firstly, } 10 \mu \mathrm{L} \text { of } 1.0 \mathrm{mg} \mathrm{L}^{-1} \text { A-MWCNT dispersion was dropped on GC. After } \\
\text { that, } 10 \mu \mathrm{L} \text { of } 1.0 \mathrm{mg} \mathrm{L}^{-1} \mathrm{GO} \text { dispersion was dropped on GC/A-MWCNT. Finally, } \\
\text { the electrode was electrochemically reduced. }\end{array}$ \\
\hline \multicolumn{2}{|c|}{$\begin{array}{l}\text { Abbreviations: GC: Glassy carbon, GO: Graphene oxide, A-MWCNT: Acid-activated multi-walled carbon nanotube, ER- } \\
\text { A-MWCNT: Electrochemically reduced acid-activated multi-walled carbon nanotube, ERGO: Electrochemically reduced } \\
\text { graphene oxide }\end{array}$} \\
\hline
\end{tabular}

\subsection{Preparation of Real Samples}

Blood serum samples were supplied from a local hospital and used without any further treatment. Urine samples were obtained from laboratory stuffs and filtered by a membrane filter $(0.45 \mu \mathrm{m})$ before use. Spiked blood serum and urine samples were prepared by mixing blood serum and standard LEV solution. To prepare pharmaceutical samples (PS), ten tablets of each PS were grinded in a mortal and a suitable amount (PS-A: $0.0230 \mathrm{~g}$, PS-B: $0.0144 \mathrm{~g}$ ) was weighed. After that, $5 \mathrm{~mL}$ acetonitrile and 10 $\mathrm{mL}$ deionized water was added to dissolve LEV and the suspension was filtered. After filtration, the solution was diluted final volume of $0.1 \mathrm{~L}$. An aliquot of the final solution was transferred into electrochemical cell and differential pulse voltammetry (DPV) measurements were performed.

\section{RESULTS AND DISCUSSION}

\subsection{Comparison of the Performances of the Modifiers}

Electrochemical behaviours of the modified electrodes were searched by cyclic voltammetry (CV) measurements in phosphate buffer solution (PBS) (pH: 2) containing $50 \mu \mathrm{M} \mathrm{LEV} \mathrm{(Fig.} \mathrm{1).} \mathrm{CV} \mathrm{of} \mathrm{bare}$ $\mathrm{GC}$ electrode showed an oxidation peak at the potential value of $+1.128 \mathrm{~V}$. This peak observed at potential values of $+1.126 \mathrm{~V},+1.044 \mathrm{~V},+1.031 \mathrm{~V}$ and $+1.049 \mathrm{~V}$ for GC/ERGO, GC/MWCNT, GC/AMWCNT and GC/ERGO/MWCNT, respectively. As can be seen, GC/ERGO electrode led to a small 
cathodic shift in the oxidation potential of LEV. On the other hand, GC/MWCNT, GC/A-MWCNT and GC/ERGO/A-MWCNT led to prominent cathodic shifts in the oxidation potential of LEV indicating an improvement in the electrochemical behaviour of LEV. While the GC/ERGO electrode led to a small increase in the oxidation peak current of LEV, GC/MWCNT, GC/A-MWCNT and GC/ERGO/AMWCNT electrodes increased the peak current tremendously. The MWCNT and A-MWCNT increased the oxidation peak current of LEV 27 and 134 times, respectively. These results indicate that the acid activation of MWCNT increased the voltammetric performance of MWCNT 5 times. This may arise from the following reasons. Acid treatment removes the impurities of MWCNT that comes from the production process, which increases the conductivity of MWCNT [20,21]. Moreover, the oxidation of MWCNT during the acid treatment leads to formation of some functional groups such as carbonyl, hydroxyl and carboxylic acids on the surface of MWCNT [20,21]. These two effects (increasing conductivity and formation of functional groups) increased the voltammetric performance of MWCNT. It is important to note that the oxidation peak current of LEV increased 293 times in the presence of GC/ERGO/A-MWCNT. This result indicates that GC/ERGO/A-MWCNT increases the electrochemical oxidation characteristic of LEV. While the ERGO film found on GC surface did not increase the electrochemical behaviour of LEV very much, its presence increased prominently the voltammetric response of A-MWCNT. This may arise from the higher electron transfer rate and higher adsorption characteristics of A-MWCNT in the presence of ERGO.

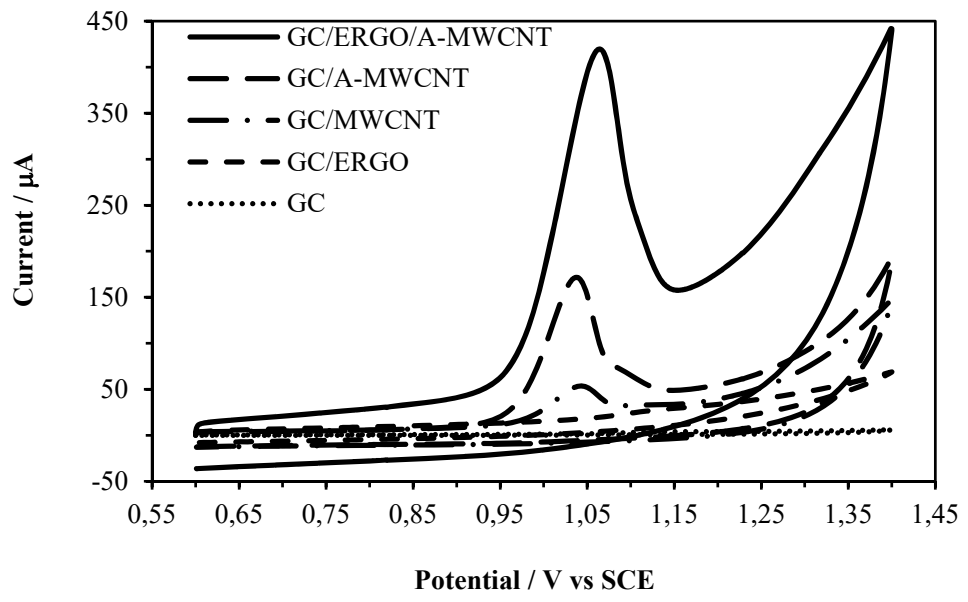

Figure 1. CVs of $50.0 \mu \mathrm{M} \mathrm{LEV} \mathrm{obtained} \mathrm{with} \mathrm{different} \mathrm{electrodes} \mathrm{in} 0.1 \mathrm{M}$ PBS (pH: 2.0). Scan rate: $0.05 \mathrm{~V} \mathrm{~s}^{-1}$, accumulation time: $180 \mathrm{~s}$, stirring rate: $300 \mathrm{rpm}$.

\subsection{Characterizations of the GC/ERGO/A-MWCNT}

Cyclic voltammograms of bare GC and the modified GC electrodes obtained in the presence of $2.5 \mathrm{mM}$ $\mathrm{Fe}(\mathrm{CN})_{6}{ }^{4-3-}$ and $1.0 \mathrm{mM} \mathrm{Ru}\left(\mathrm{NH}_{2}\right)_{6}{ }^{3+}$ are shown in Figure 2. An oxidation peak at the potential of +0.240 $\mathrm{V}$ and a reduction peak at $+0.125 \mathrm{~V}$ were observed in $\mathrm{CV}$ of $\mathrm{Fe}(\mathrm{CN})_{6}{ }^{4-/ 3-}$ redox couple when the working electrode was bare GC (Fig. 2A-a). A negative effect was observed at the peak potentials of $\mathrm{Fe}(\mathrm{CN})_{6}{ }^{4-}$ /3- redox couple when the GC electrode surface was covered with ERGO (Fig. 2A-b). On the other hand, the peak currents of $\mathrm{Fe}(\mathrm{CN})_{6}^{4-/ 3-}$ redox couple were gradually increased when the GC/MWCNT (Fig. 2A-c) and GC/A-MWCNT (Fig. 2A-d) electrodes were used. This indicates that the effective surface area of GC electrode increases in the presence of MWCNT and A-MWCNT films. The highest peak currents were observed once the GC/ERGO/A-MWCNT electrode was used in the experiments (Fig. $2 \mathrm{~A}-\mathrm{e})$. The peak separation values were calculated as $0.115,0.595,0.113,0.108$ and $0.137 \mathrm{~V}$ for GC, GC/ERGO, GC/MWCNT, GC/A-MWCNT and GC/ERGO/A-MWCNT, respectively. As can be seen, all the studied electrodes gave almost the same peak separation except GC/ERGO electrode. 
The electrochemical behaviour of $\mathrm{Ru}\left(\mathrm{NH}_{2}\right)_{6}{ }^{3+}$ was also investigated with the modified electrodes (Fig. 2B). A similar trend like $\mathrm{Fe}(\mathrm{CN})_{6}{ }^{4-3-}$ was observed in the case of $\mathrm{Ru}\left(\mathrm{NH}_{2}\right)_{6}{ }^{3+}$. The highest peak currents were obtained with GC/ERGO/A-MWCNT indicating efficiency of the used modification.
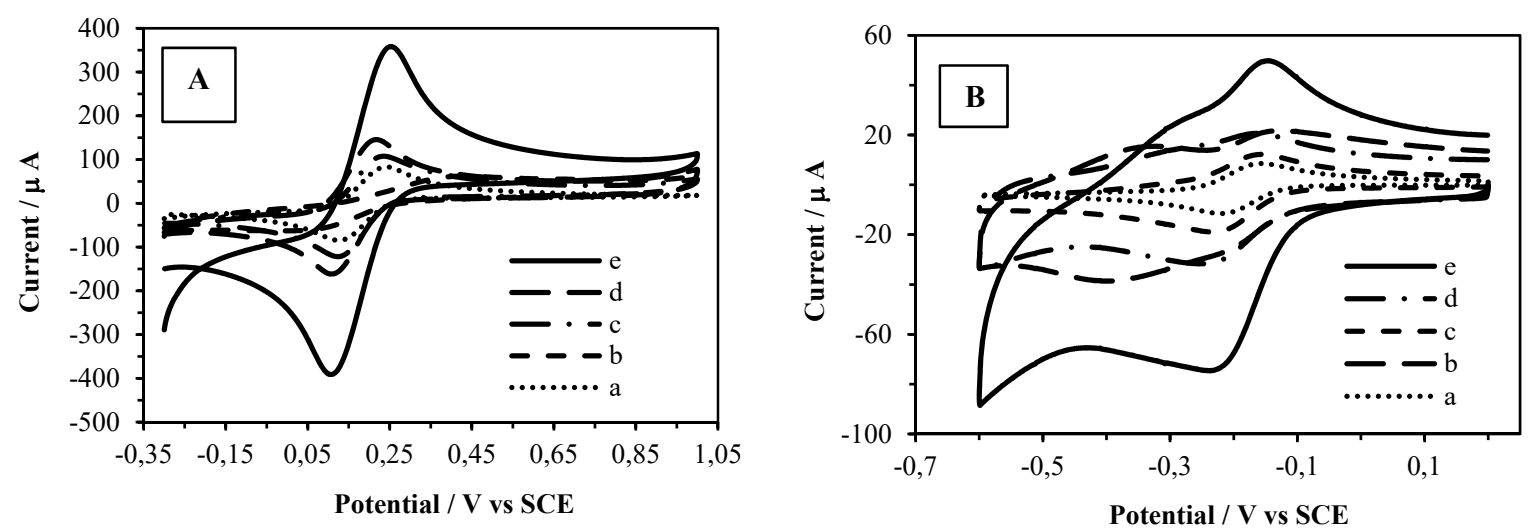

Figure 2. $\mathrm{CVs}$ of $2.5 \mathrm{mM} \mathrm{K}{ }_{3} \mathrm{Fe}(\mathrm{CN})_{6} / \mathrm{K}_{4} \mathrm{Fe}(\mathrm{CN})_{6}(\mathrm{~A})$ and $1.0 \mathrm{mM} \mathrm{Ru}\left(\mathrm{NH}_{2}\right)_{6}{ }^{3+}$ (B) obtained with $\mathrm{GC}$ (a), GC/ERGO (b), GC/MWCNT (c), GC/A-MWCNT (d) and GC/ERGO/A-MWCNT (e) in $0.1 \mathrm{M} \mathrm{KCl.}$ Scan rate: $0.05 \mathrm{~V} \mathrm{~s}^{-1}$.

Raman measurements were used to evaluate the formation of graphene on the electrode surface by electrochemical reduction. The Raman spectrums of GO and ERGO were given in Figure 3. As can be seen, two bands at wavenumbers of $1335 \mathrm{~cm}^{-1}$ and $1576 \mathrm{~cm}^{-1}$ were observed for both GO and ERGO. These bands correspond to characteristic D and $\mathrm{G}$ bands of graphene [22]. The intensities of these bands were prominently increased after electrochemical reduction indicating the increase of graphene structure on the electrode surface.

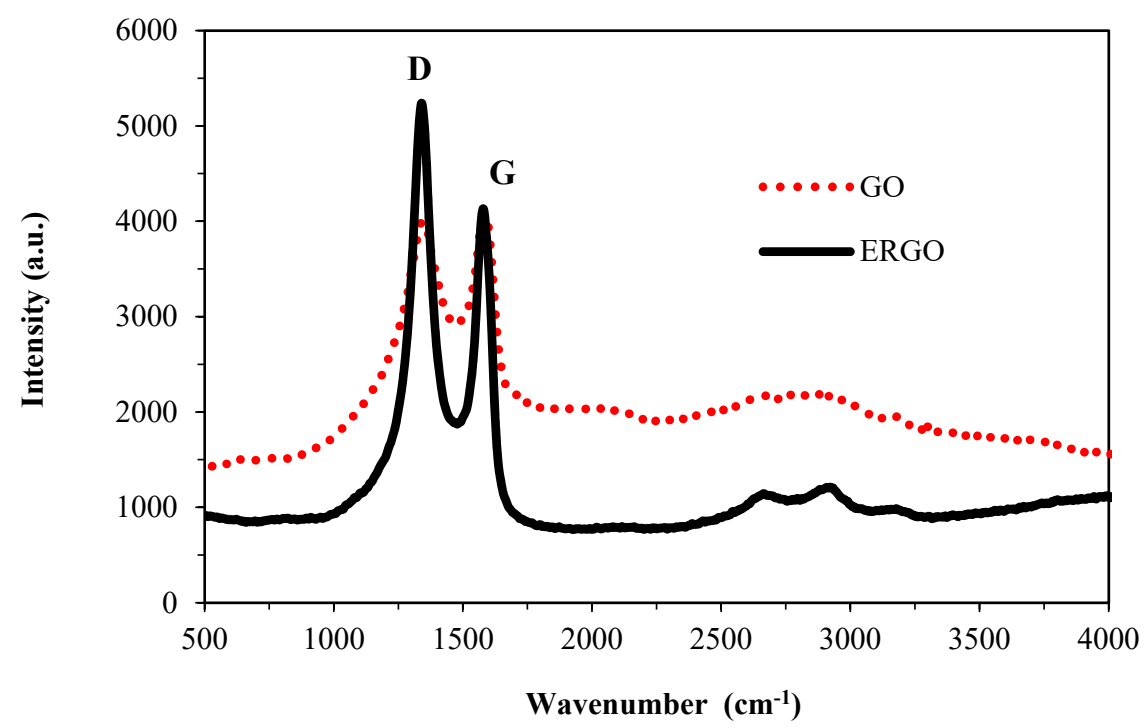

Figure 3. Raman spectrums of GO and ERGO obtained with electrochemical reduction via cyclic voltammetry measurements between the potential values of $0.0 \mathrm{~V}$ and $-1.5 \mathrm{~V}$ with a scan rate of $0.05 \mathrm{~V} \mathrm{~s}^{-1}$ for 10 scans.

\subsection{Optimization of the Parameters}

The effect of $\mathrm{pH}$ was examined by performing DPV measurements of 5.0 $\mu \mathrm{M}$ LEV with GC/ERGO/AMWCNT at different $\mathrm{pH}$ values. The oxidation peak currents decreased tremendously by the increase of $\mathrm{pH}$ from 2.0 to 7.4. A small increase was seen at $\mathrm{pH}$ value of 8.5. The highest oxidation peak current 
of LEV was obtained at $\mathrm{pH}$ value of 2.0. Therefore, this $\mathrm{pH}$ was selected as the optimal $\mathrm{pH}$. Different $\mathrm{pH}$ values such as 4.5 [10], 5.5 [9] and 6.0 [21] were also reported as the optimal values in the presence of different modified electrodes. These results indicate that the GC/ERGO/A-MWCNT showed different characteristics from the previously reported modified electrodes.

The effect of accumulation time on the oxidation peak currents of LEV was also examined. A gradual increase was seen in the oxidation peak currents when the accumulation time was increased from $30 \mathrm{~s}$ to $180 \mathrm{~s}$. After this time, further increase of accumulation time did not lead to any meaningful increase in current values.

\subsection{Investigation of the Effects of Interfering Substances}

DPV measurements of LEV were performed with GC/ERGO/A-MWCNT in the absence and presence of some possible interfering substances to investigate the effects of these substances. First of all, the effects of structurally related substances such as ciprofloxacin, enoxacin and norfloxacin were searched. Differential pulse voltammograms of $2.5 \mu \mathrm{M}$ LEV in the absence and presence of two-fold excess ciprofloxacin, enoxacin and norfloxacin were recorded (Fig. 4). As can be seen, the GC/ERGO/AMWCNT successfully separate the oxidation potential of LEV from those of enoxacin, norfloxacin and ciprofloxacin. These results indicate that the GC/ERGO/A-MWCNT allows the selective determination of LEV in the presence of other fluoroquinolone antibiotics. This is a very important property because these substances have very similar structures with LEV. The effects of possible interfering substances (ascorbic acid, citric acid, paracetamol and tartaric acid) were also evaluated. The results indicate that the GC/ERGO/A-MWCNT electrode can be safely used in the determination of LEV in the presence of these substances.
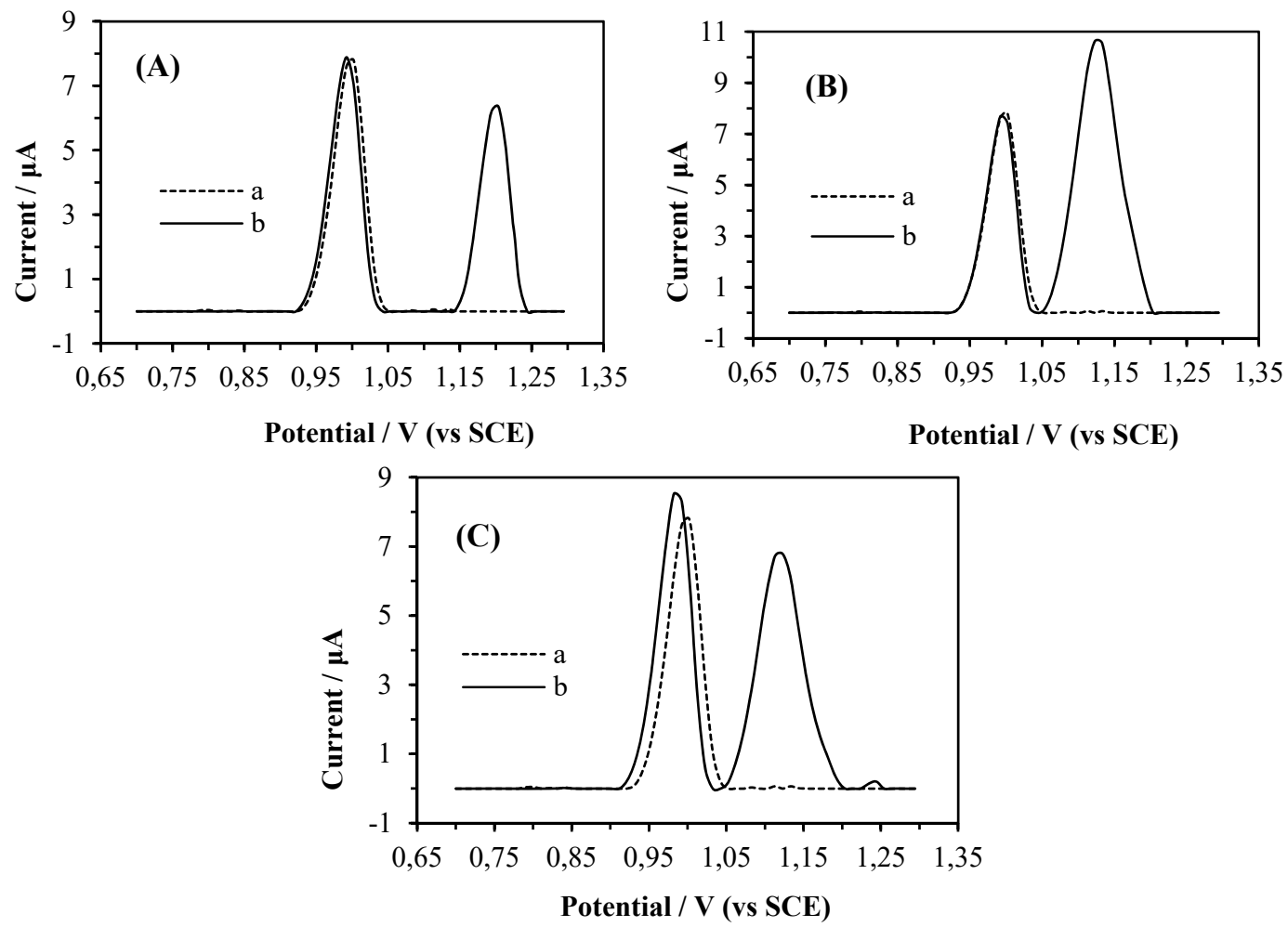

Figure 4. DPVs of $2.5 \mu \mathrm{M}$ LEV in PBS (pH: 2.0) in the absence (a) and presence (b) of $5.0 \mu \mathrm{M}$ enoxacin (A), ciprofloxacin (B) and norfloxacin (C). Accumulation time: $60 \mathrm{~s}$, Stirring rate $300 \mathrm{rpm}$. 


\subsection{Stability, Reproducibility and Regeneration of GC/ERGO/A-MWCNT}

Stability of GC/ERGO/A-MWCNT was tested by performing DPV measurements of 5.0 $\mu \mathrm{M}$ LEV over three weeks. The electrodes were stored in a desiccator during this period. The electrode kept $91 \%$ of its initial activity towards LEV after a 20-day storage. These results indicate that the modified electrode can be stored for a long time without any significant activity loss.

Reproducibility of the GC/ERGO/A-MWCNT electrode was investigated in three headings; intra-day, inter-day and fabrication reproducibility. Differential pulse measurements were performed with GC/ERGO/A-MWCNT electrode ten times in a solution containing 1.0 $\mu \mathrm{M} \mathrm{LEV}$. The relative standard deviation (RSD) of these measurements was calculated as $2.92 \%$ which represents intra-day reproducibility. To determine inter-day reproducibility, differential pulse measurements were repeated with the same GC/ERGO/A-MWCNT electrode for ten days. The RSD value of inter-day measurements was obtained as $3.45 \%$. The fabrication reproducibility of GC/ERGO/A-MWCNT electrode was tested by preparing ten different electrodes and determining their voltammetric responses. The RSD of the measurements was determined as $4.26 \%$. The results obtained indicate that the GC/ERGO/A-MWCNT electrode produces very reproducible results.

The regeneration of the electrode surface was also investigated. For this purpose, DPVs of 5.0 $\mu \mathrm{M} \mathrm{LEV}$ in PBS (pH: 2.0) was performed (Fig. 5a). After that, the electrode was placed in a blank PBS (pH: 2.0) and DPV measurement was repeated (Fig. 5b). A very small oxidation peak which belongs to LEV was noticed in blank DPV measurement (Fig. 5b). This indicates that there was an adsorption of LEV on the electrode surface, but the amount of this adsorption was very small. In a separate experiment, firstly, DPV measurement of 5.0 $\mu \mathrm{M}$ LEV was performed. After that, the electrode was waited in a PBS (pH: 5.0) under stirring conditions. After 2 min, the electrode was placed in a blank PBS (pH: 2.0) and DPV measurement was done (Fig. 5c). As can be seen, no meaningful LEV signal was observed in blank measurement. This indicates that the electrode can be easily regenerated by waiting in PBS (pH: 5.0) for $2 \mathrm{~min}$. This property is very important for the modified GC electrodes because one of the most important problem in modified electrodes is the regeneration of the electrode surface.

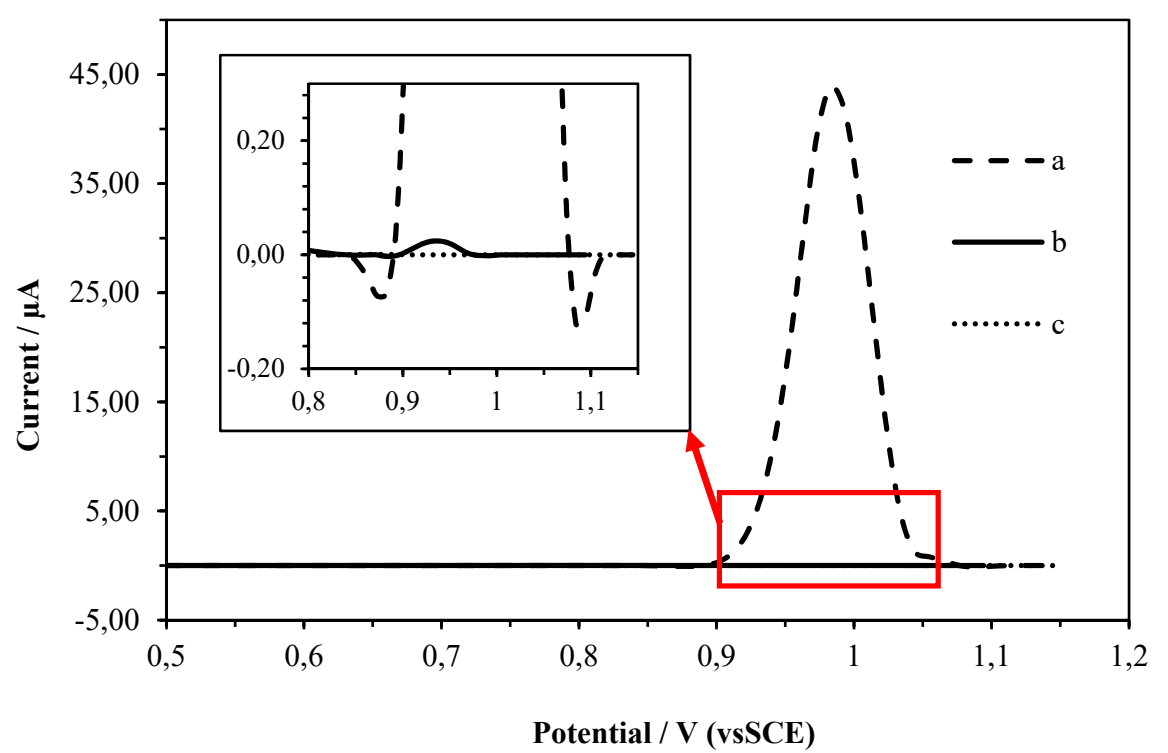

Figure 5. a) DPV of GC/ERGO/A-MWCNT in PBS (pH: 2) containing $5.0 \mu \mathrm{M} \mathrm{LEV.} \mathrm{b)} \mathrm{DPV} \mathrm{of} \mathrm{GC/ERGO/A-}$ MWCNT in PBS ( $\mathrm{pH}$ 2) after waiting the electrode in deionized water for 2 min after performing the measurement a. c) DPV of GC/ERGO/A-MWCNT in PBS (pH 2) after waiting the electrode in PBS (pH 5.0) for 2 min after performing the measurement a. Accumulation time: $180 \mathrm{~s}$, stirring rate: $300 \mathrm{rpm}$. 
Attlır Özcan et al. / Anadolu Univ. J. of Sci. and Technology A - Appl. Sci. and Eng. 18 (5) - 2017

\subsection{Determination of Analytical Parameters}

Analytical parameters of the GC/ERGO/A-MWCNT were determined in a solution containing different amount of LEV. A linear region was observed between the oxidation peak currents of LEV and its concentrations. The corresponding line has an equation of $I_{p}(\mu A)=8.80 C_{L E V}(\mu M)+0.72$ in the concentration range of 0.01-10.0 $\mu \mathrm{M}$. Limit of detection (LOD) and limit of quantification (LOQ) values of the method proposed in this study were calculated as $0.0063 \mu \mathrm{M}(\mathrm{S} / \mathrm{N}: 3)$ and $0.021 \mu \mathrm{M}(\mathrm{S} / \mathrm{N}: 10)$, respectively. Analytical parameters of the GC/ERGO/A-MWCNT were compared in Table 2 with those of other modified electrodes. The modified electrode showed superior performance than the previously reported modified electrodes.

Table 2. Comparison of the performances of various modified electrodes

\begin{tabular}{|c|c|c|c|c|c|}
\hline Electrode type & $\begin{array}{l}\text { Linear } \\
\text { range }\end{array}$ & $\begin{array}{l}\text { LOD } \\
(\mu \mathrm{M})\end{array}$ & $\begin{array}{l}\text { LOQ } \\
(\mu \mathrm{M})\end{array}$ & Method & Reference \\
\hline Molecularly imprinted polymer/graphene-gold & $1-100$ & 0.53 & 1.77 & DPV & [3] \\
\hline $\begin{array}{l}\text { Silver nanoparticles-cesium oxide-gold-glassy } \\
\text { carbon }\end{array}$ & $0.03-10$ & 0.01 & 0.033 & DPV & [9] \\
\hline Poly(aminophenol)/MWCNTs & $3.00-200$ & 1.00 & 3.33 & DPV & [10] \\
\hline Single-strand DNA-SWCNT-gold & $1-10$ & 0.075 & 0.25 & SWV & [23] \\
\hline MWCNTs-poly(alizarin) & $5.00-100$ & 0.40 & 1.33 & LSV & [24] \\
\hline Double-strand DNA-glassy carbon & $0.5-5$ & 0.10 & 0.33 & SWV & {$[25]$} \\
\hline $\begin{array}{l}\text { Poly(diallyldimethylammonium chloride)-reduced } \\
\text { graphene oxide-gold nanoparticles }\end{array}$ & $10-200$ & 3.90 & 13.00 & LSV & [26] \\
\hline GC/ERGO/A-MWCNT & $0.01-10$ & 0.0063 & 0.021 & DPV & This work \\
\hline
\end{tabular}

\subsection{Analysis of Real Samples}

The determination of LEV in urine, blood serum and pharmaceutical samples was investigated with GC/ERGO/A-MWCNT to evaluate the applicability of the modified electrode in real samples. Firstly, the performance of the GC/ERGO/A-MWCNT was tested in pharmaceutical samples. Two different pharmaceutical samples were taken and their LEV contents were determined. DPVs of the first sample were given in Figure 6. As can be seen, an oxidation peak was observed at $+0.968 \mathrm{~V}$ corresponding to the LEV. The intensity of this peak increased after each addition of standard LEV solution (Fig. 6). The second sample was also analysed in the same way. Their LEV contents were determined as $0.4900 \mathrm{~g}$ tablet $^{-1}$ and $0.4920 \mathrm{~g}$ tablet $^{-1}$. These values were very close to their initial values of $0.5000 \mathrm{~g} \mathrm{tablet}^{-1}$ indicated by the producers. Analytical application of the GC/ERGO/A-MWCNT was also tested in blood serum and urine samples. The recovery analysis was performed with these samples because they initially did not contain any LEV. The analysis of spiked blood serum and urine samples were performed by standard addition method. The recovery values obtained during these analyses were given in Table 3. As can be seen, satisfactory results were obtained in the case of both samples. These results indicate that the GC/ERGO/A-MWCNT can be safely used in the determination of LEV in such kind of samples. 
Atılır Özcan et al. / Anadolu Univ. J. of Sci. and Technology A - Appl. Sci. and Eng. 18 (5) - 2017

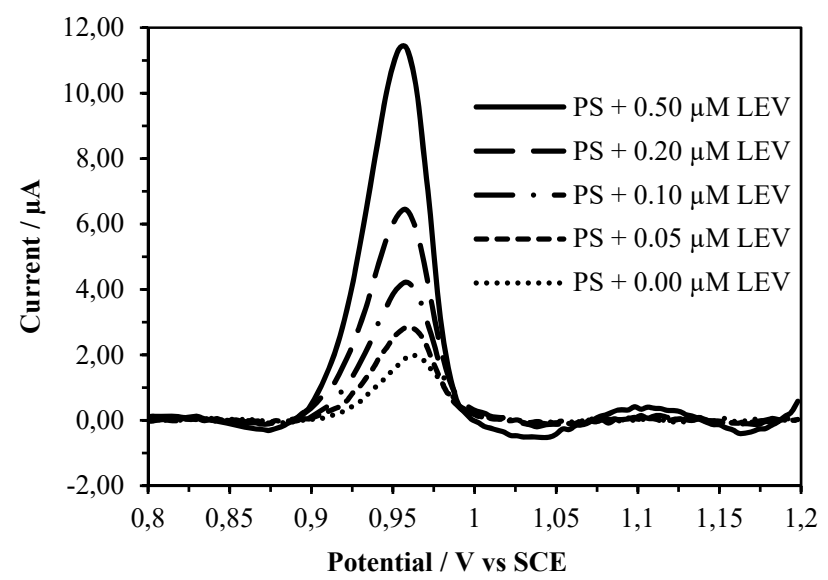

Figure 6. DPVs of GC/ERGO/A-MWCNT in PBS (pH: 2) containing thousand-time diluted pharmaceutical sample in the presence of increasing concentrations of LEV. Accumulation time: $180 \mathrm{~s}$, stirring rate: $300 \mathrm{rpm}$.

Table 3. The results of the determination of LEV in spiked blood serum and urine samples

\begin{tabular}{llll}
\hline Sample & Spiked value $/ \mu \mathrm{M}$ & Determined value $/ \mu \mathrm{M}$ & \% Recovery \\
\hline BS-A & 0.200 & 0.197 & 98.5 \\
BS-B & 0.500 & 0.5125 & 102.5 \\
US-A & 0.400 & 0.389 & 97.25 \\
US-B & 1.000 & 1.097 & 109.7 \\
\hline
\end{tabular}

\section{CONCLUSIONS}

The application of carbon nanomaterials (GO and A-MWCNT) was investigated at different combinations to prepare an electrochemical LEV sensor. GC/ERGO/A-MWCNT electrode showed the highest oxidation peak current in the oxidation of LEV among the studied combinations. Different parameters were searched to increase the sensitivity of the modified electrode. The electrode showed superior performances according to GC in the electrochemical oxidation of LEV by increasing peak currents tremendously and discriminating the oxidation potential of LEV from other substances. The real sample analysis with GC/ERGO/A-MWCNT gave satisfactory results. According to obtained results, it can be concluded that the GC/ERGO/A-MWCNT electrode is a good candidate for the determination of LEV because of its properties such as simplicity, easy preparation, high reproducibility and high sensitivity.

\section{ACKNOWLEDGEMENTS}

This study was supported by the Anadolu University Scientific Research Projects Commission under the grant number of $1605 \mathrm{~F} 334$.

\section{REFERENCES}

[1] Basu PP, Rayapudi K, Pacana T, Shah NJ., Krishnaswamy N, Flynn M. A Randomized Study Comparing Levofloxacin, Omeprazole, Nitazoxanide, and Doxycycline versus Triple Therapy for the Eradication of Helicobacter pylori. Am J Gastroenterol 2011; 106; 1970-1975.

[2] Aguilar-Carrasco JC., Hernández-Pineda J, Jiménez-Andrade JM, Flores-Murrieta FJ., CarrascoPortugal MC, López-Canales JS. Rapid and sensitive determination of levofloxacin in microsamples of human plasma by high-performance liquid chromatography and its application in a pharmacokinetic study. Biomed Chromatogr 2015; 29; 341-345. 
[3] Wang F, Zhu L, Zhang J. Electrochemical sensor for levofloxacin based on molecularly imprinted polypyrrole-graphene-gold nanoparticles modified electrode. Sens Actuat B Chem 2014; 192; 642647.

[4] Locatelli M, Ciavarella MT, Paolino D, Celia C, Fiscarelli E, Ricciotti G, Pompilio A, Bonaventura GD, Grande R, Zengin G, Marzio LD. Determination of ciprofloxacin and levofloxacin in human sputum collected from cystic fibrosis patients using microextraction by packed sorbent-high performance liquid chromatography photodiode array detector, J Chromatogr A 2015; 1419; 58-66.

[5] Lee SJ, Desta KT, Eum SY, Dartois V, Cho SN, Bae DW, Shin SC. Development and validation of LC-ESI-MS/MS method for analysis of moxifloxacin and levofloxacin in serum of multidrugresistant tuberculosis patients: Potential application as therapeutic drug monitoring tool in medical diagnosis. J. Chromatogr B Anal Technol Biomed Life Sci 2016; 1009-1010; 138-143.

[6] Herrera-Herrera AV, Ravelo-Pérez LM, Hernández-Borges J, Afonso MM, Palenzuela JA, Rodríguez-Delgado M.Á. Oxidized multi-walled carbon nanotubes for the dispersive solid-phase extraction of quinolone antibiotics from water samples using capillary electrophoresis and large volume sample stacking with polarity switching. J Chromatogr A 2011; 1218;5352-5361.

[7] Shao X, Li Y, Liu Y, Song Z. Flow injection chemiluminescence determination of levofloxacin in medicine and biological fluids based on its enhancing effect on luminol-H2O2 reaction. Spectroscopy 2009; 23; 209-216.

[8] Mazzotta E, Malitesta C, Díaz-Álvarez M, Martin-Esteban A. Electrosynthesis of molecularly imprinted polypyrrole for the antibiotic levofloxacin. Thin Solid Films 2012; 520; 1938-1943.

[9] Tang L, Tong Y, Zheng R, Liu W, Gu Y, Li C, Chen R, Zhang Z. Ag nanoparticles and electrospun $\mathrm{CeO} 2-\mathrm{Au}$ composite nanofibers modified glassy carbon electrode for determination of levofloxacin. Sens Actuat B Chem 2014; 203; 95-101.

[10] Wen W, Zhao DM., Zhang XH, Xiong HY, Wang SF, Chen W, Zhao YD. One-step fabrication of poly(o-aminophenol)/multi-walled carbon nanotubes composite film modified electrode and its application for levofloxacin determination in pharmaceuticals. Sens Actuat B Chem 2012; 174; 202 209.

[11] Tajabadi MT, Sookhakian M, Zalnezhad E, Yoon GH, Hamouda AMS, Azarang M, Basirun WJ, Alias Y. Electrodeposition of flower-like platinum on electrophoretically grown nitrogen-doped graphene as a highly sensitive electrochemical non-enzymatic biosensor for hydrogen peroxide detection. Appl Surf Sci 2016; 386; 418-426.

[12] Ban FY, Jayabal S, Lim HN, Lee HW, Huang NM. Synthesis of nitrogen-doped reduced graphene oxide-multiwalled carbon nanotube composite on nickel foam as electrode for high-performance supercapacitor. Ceram Int 2017; 43; 20-27.

[13] Akkarachanchainon N, Rattanawaleedirojn P, Chailapakul O, Rodthongkum N. Hydrophilic graphene surface prepared by electrochemically reduced micellar graphene oxide as a platform for electrochemical sensor. Talanta 2017; 165; 692-701.

[14] Guo CX, Li CM. A self-assembled hierarchical nanostructure comprising carbon spheres and graphene nanosheets for enhanced supercapacitor performance. Energy Environ Sci 2011; 4; 45044507. 
Atılır Özcan et al. / Anadolu Univ. J. of Sci. and Technology A - Appl. Sci. and Eng. 18 (5) - 2017

[15] Yoo EJ, Kim J, Hosono E, Zhou HS, Kudo T, Honma I. Large reversible Li storage of graphene nanosheet families for use in rechargeable lithium ion batteries. Nano Lett 2008; 8; 2277-2282.

[16] Giannouri M, Bidikoudi M, Pastrana-Martínez LM, Silva AMT, Falaras P. Reduced graphene oxide catalysts for efficient regeneration of cobalt-based redox electrolytes in dye-sensitized solar cells. Electrochim Acta 2016; 219; 258-266.

[17] Mukdasai S, Langsi V, Pravda M, Srijaranai S, Glennon JD. A highly sensitive electrochemical determination of norepinephrine using 1-cysteine self-assembled monolayers over gold nanoparticles/multi-walled carbon nanotubes electrode in the presence of sodium dodecyl sulfate. Sens Actuat B Chem 2016; 236; 126-135.

[18] Taei M, Salavati H, Hasanpour F, Habibollahi S, Baghlani H. Simultaneous determination of ascorbic acid, acetaminophen and codeine based on multi-walled carbon nanotubes modified with magnetic nanoparticles paste electrode. Mater Sci Eng C 2016; 69; 1-11.

[19] Silva TA, Zanin H, Vicentini FC, Corat EJ, Fatibello-Filho O. Electrochemical determination of rosuvastatin calcium in pharmaceutical and human body fluid samples using a composite of vertically aligned carbon nanotubes and graphene oxide as the electrode material. Sens Actuat B Chem 2015; $218 ; 51-59$.

[20] Karthik R, Sasikumar R, Chen SM, Vinoth Kumar J, Elangovan A, Muthuraj V, Muthukrishnan P, Al-Hemaid FMA, Ajmal Ali M, Elshikh MS. A highly sensitive and selective electrochemical determination of non-steroidal prostate anti-cancer drug nilutamide based on f-MWCNT in tablet and human blood serum sample. J Coll Interf Sci 2017; 487; 289-296.

[21] Gómez S, Rendtorff NM, Aglietti EF, Sakka Y, Suárez G. Surface modification of multiwall carbon nanotubes by sulfonitric treatment. Appl Surf Sci 2016; 379; 264-269.

[22] Raj MA, John SA. Fabrication of Electrochemically reduced graphene oxide films on glassy carbon electrode by self-assembly method and their electrocatalytic application. J Phys Chem C 2013; 117; $4326-4335$.

[23] Moraes FC, Silva TA, Cesarino I, Lanza MRV, Machado SAS. Antibiotic detection in urine using electrochemical sensors based on vertically aligned carbon nanotubes, Electroanalysis 2013; 25; 2092-2099.

[24] Chi Y, Li J. Determination of levofloxacin hydrochloride with multiwalled carbon nanotubespolymeric alizarin film modified electrode. Russ J Electrochem 2010; 46; 155-160.

[25] Radi A, El Ries MA., Kandil S. Electrochemical study of the interaction of levofloxacin with DNA. Anal Chim Acta 2003; 495; 61-67.

[26] Borowiec J, Yan K, Tin CC, Zhang J. Synthesis of PDDA Functionalized Reduced Graphene Oxide Decorated with Gold Nanoparticles and Its Electrochemical Response toward Levofloxacin J Electrochem Soc 2015; 162; H164-H169. 